\title{
Evaluation on the Soil Flexibility of the Largest HEP Dam Area in East Malaysia using 1-D Equivalent Linear Analysis
}

\author{
Raudhah Ahmadi ${ }^{\mathrm{a},}$, , Muhammad Haniz Azahari Muhamad Suhailia ${ }^{\mathrm{a}}$ Imtiyaz Akbar Najar ${ }^{\mathrm{a}}$, Muhammad \\ Azmi Ladi ${ }^{\mathrm{b}}$, Nisa Aqila Bakie ${ }^{\mathrm{c}}$, Ahmed Faysal Abdullahi ${ }^{\mathrm{d}}$ \\ ${ }^{a}$ Department of Civil Engineering, Faculty of Engineering, Universiti Malaysia Sarawak, Kota Samarahan, 94300, Sarawak, Malaysia \\ ${ }^{b}$ Kuching Polytechnic, Jalan Matang, Petra Jaya, 93050, Sarawak, Malaysia \\ ${ }^{c}$ School of Engineering and Technology, University College of Technology Sarawak, Sibu, 96000, Sarawak, Malaysia \\ ${ }^{d}$ School of Civil Engineering and Built Environment, Liverpool John Moores University, Liverpool, United Kingdom
}

Corresponding author: *araudhah@unimas.my

\begin{abstract}
This paper presents the evaluation of soil flexibility at the vicinity of the Bakun HEP Dam, the largest in East Malaysia. The dam is located in the Belaga District of Sarawak, approximately $50 \mathrm{~km}$ from the active Tubau and Bukit Mersing fault lines. This area experienced earthquakes of magnitudes ranging between 3.5 and 5.4 during the period from 1994 and 2010. This study used global and local earthquake records to evaluate the site-specific seismic hazard using a 1-D equivalent linear analysis. SPT data from 15 boreholes are utilized. Soil flexibility, factor of safety, liquefaction probability and potential index are evaluated to find the ground settlement and soil liquefaction effects. The results show that the ground amplification of Belaga District is between 2.445 and 5.146, while the peak ground accelerations (PGA) at ground surface are at a maximum average of 0.25g PGA. The soil factors for Bakun District range from 2.6 - 3.0, for $2 \%$ POE in 50 years. This corresponds to a 2475 -year return period. The response spectra are found matching with the target design response spectra for Sarawak as reported in the Malaysia National Annex (MS EN 1998-1:2015). The effects of soil liquefaction are found to be insignificant, as a result the nearby Bakun HEP dam is considered safe from any ground settlement. This study highlights the importance of evaluating the ability of new or existing structures in Belaga District to withstand up to 0.25g PGA in case any seismic event should occur in the future.
\end{abstract}

Keywords - Soil flexibility; Belaga district Sarawak; seismic design response spectra; soil liquefaction hazard assessment.

\section{INTRODUCTION}

Historically, East Malaysia was not considered an area exposed to any significant seismic activity or events. East Malaysia is situated within stable and on the exterior of the seismic zone [1]. The nearest seismic zone is the Philippines Sea Plate, which shifts to the west at a rate of $80 \mathrm{~mm} /$ year. This area is exposed to earthquakes of significant magnitudes centered around the Southern Philippines, the Makassar Strait, the Sulu Sea, and the Celebes Sea, as shown in Figure 1 [2].

In the past 20 years, East Malaysia, a combination of the two states of Sabah and Sarawak, seldom experienced any large earthquakes until recently, in June 2015, when an earthquake of magnitude $\mathrm{M}_{\mathrm{w}} 5.9$ struck Ranau, Sabah. This is the largest earthquake experienced in Malaysia [3]. Due to this event, more seismic monitoring stations are being built in East Malaysia to monitor any seismic activity. Seismologists have realized that many local faults are in Sabah and Sarawak, which have become active over the years. This is genuinely concerning due to the number of existing and newly constructed dams available in Sabah and Sarawak. Due to the vast potential in Sarawak, many large hydropower electric dams are planned for future construction to supply electricity. These essential and large structures require detailed seismic assessment in the planning, design, construction, and operation stage.

Three large dams, Bakun, Murum, and Baleh, are in a 120 $\mathrm{km}$ radius of the Kapit-Belaga region in Sarawak, where the new dextral strike-slip deflected streams and sinistral faults are found along the Rajang-Crocker Belt [4].

The active Tubau fault line extends a $100 \mathrm{~km}$ north to south and spans from Belaga in the south to Niah in the north, as shown in Figure 2. Two earthquakes were caused by the Tubau fault, one in May $2004\left(\mathrm{M}_{\mathrm{w}} 5.2\right)$ and another in January 